\title{
VULVOVAGINAL CANDIDIASIS IN COMBINATION WITH BACTERIAL VAGINOSIS IN WOMEN OF REPRODUCTIVE AGE: FEATURES OF PATHOGENESIS AND TREATMENT
}

\author{
Svitlana Pandei \\ Department of Obstetrics, Gynecology and Perinatology ${ }^{I}$ \\ Dmytro Ledin \\ Department of Obstetrics, Gynecology and Perinatology ${ }^{l}$ \\ Oleksandra Lubkovska \\ Department of Obstetrics, Gynecology and Perinatology ${ }^{l}$ \\ ${ }^{1}$ Ukrainian State Institute of Reproductology \\ Shupyk National Medical Academy of Postgraduate Education \\ 9 Dorohozhytska str., Kyiv, Ukraine, 04112
}

\begin{abstract}
The aim. Reducing the recurrence of vulvovaginal candidiasis (VVC) in combination with bacterial vaginosis (BV) in women of reproductive age by studying the pathogenesis and improving the algorithm of treatment and prevention measures.

Materials and methods. During the study, 150 women of reproductive age who had the same clinical manifestations of VVC and BV were selected and divided into 3 groups of 50 women: Group I was treated with an antimicrobial combination drug (miconazole with topical metronidazole), group II - the same drug in combination with probiotic (lactobacilli) in candles, group III - according to the algorithm improved by the authors. In addition, a control group was formed, which included healthy women of reproductive age.

To establish the pathogenesis of VVC in combination with BV in the studied women, the concentration of cytokines and adhesion molecules in the blood before and after treatment was determined and compared with the control group. The clinical effect of different treatments was assessed at 3, 7, 10, 14 days, and the presence of relapses - 1, 3, 6 months after treatment.

Results. The occurrence of a combination of VVC and BV in women of reproductive age is accompanied by a significant increase in the level of intercellular adhesion molecules (ICAM-1) and vascular cell adhesion molecules (VCAM-1) along with a statistically significant increase in proinflammatory cytokines (interleukin-6) (IL-6), interleukin-8 (IL-8)) and tumor necrosis factor (TNF) - TNF- $\alpha$. As a result of the application of the algorithm improved by the authors, higher clinical efficiency and the ability to avoid recurrence of VVC in combination with $\mathrm{BV}$ in women of reproductive age were obtained.

Conclusions. The authors' substantiated improvement of the algorithm of VVC treatment in combination with BV in women of reproductive age makes it possible to reduce the frequency of their recurrence and restore the biocenosis of the vagina to normal. In the case of this pathology there is an increase in the level of pro-inflammatory cytokines (IL-6, IL-8), TNF- $\alpha$ and ICAM-1 and VCAM-1.
\end{abstract}

Keywords: candidal vulvovaginitis, bacterial vaginosis, reproductive age, cytokines, adhesion molecules.

DOI: $10.21303 / 2504-5679.2021 .001624$

\section{Introduction}

A woman's reproductive health largely depends on the normal state of the microbiocenosis of the genital tract, in particular, infectious and inflammatory processes caused by vaginal dysbiosis can adversely affect maternal health, pregnancy, childbirth and fetal status [1,2].

In healthy women of reproductive age against the background of species diversity, the leading place in the vaginal microbiocenosis is occupied by lactobacilli of both aerobic and anaerobic origin, as well as the presence of a small amount of Peptostreptococcus, Bifidobacterium, Clostridium, Propionibacterium, Bacteroides, gardnerella and fungi of the genus Candida. Lactobacilli inhabit the mucous membrane of a woman's vagina and perform metabolic and barrier functions. Their protective role is manifested by antagonistic activity against other microorganisms, they synthesize lactic acid, peroxides and lysozyme with adhesive action. Colonization resistance is formed by lactobacilli due to acid formation and formation of hydrogen peroxide [3, 4].

In turn, dysbiosis is characterized by a significant reduction, in particular to the complete absence of lactobacilli, significant polymorphic gram-negative and gram-positive rod and coccal flora, as well as an increased number of fungi of the genus Candida, «key» cells, etc. $[5,6]$. 
The causative agent of candidal vulvovaginitis is a yeast-like fungus of the genus Candida. However, Candida albicans is the dominant cause of VVC. It is characterized, on the one hand, by a high prevalence, and on the other - the acquisition of a chronic nature with frequent recurrences, which not only increases the risk of reproductive health disorders, but also significantly reduces its quality of life with the possibility of pathologies of other body systems [7, 8].

At the same time, the disadvantage of VVC as such is only exacerbated by the accession of $\mathrm{BV}$, as it increases the pathological effect on the body of a woman, complicates its diagnosis, treatment, restoration of normocenosis and avoid recurrence.

The aim - reducing the recurrence rate of VVC in combination with BV in women of reproductive age by studying the pathogenesis and improving the algorithm of treatment and prevention measures.

\section{Materials and methods}

The study was conducted from 2018 to 2020 on the basis of the Department of Obstetrics, Gynecology and Perinatology on the basis of the Kyiv Maternity Hospital G1 and the Clinic named after prof. A. M. Feskov in Ukraine.

The study was conducted in compliance with all the rules in accordance with the Declaration of Helsinki according to the conclusion of the Commission on Ethics of the National Medical Academy of Postgraduate Education named after P. L. Shupyk (minutes No. 3 from 25.01.2018). All women received informed consent for appropriate research and use of the drugs.

The study included 150 women of reproductive age who had both VVC and BV. Complaints included itching of the vulva, burning when urinating and abnormal discharge from the genital tract. Gynecological examination also showed characteristic signs of these pathological conditions, namely: hyperemia, edema of the vulva, vaginal mucosa and cervix, «curd» or watery discharge. However, before this study, women did not receive treatment for these complaints. After appropriate examination, all women were found to have Candida albicans, non-albicans and «key» cells.

In order to identify the pathogenesis of VVC in combination with $\mathrm{BV}$, as well as to evaluate the effectiveness of the proposed algorithm of treatment and prevention measures from the standpoint of improving the effectiveness of treatment of these diseases in women of reproductive age and reduce their recurrence, all women were divided into three groups depending on the method treatment. Group I included 50 women who were treated with an antimicrobial combination drug, namely miconazole with topical metronidazole. Group II - 50 women who were treated with the same drug in combination with probiotics (lactobacilli) in candles. To group III - 50 women who received treatment according to the algorithm improved by the authors, which consisted of additional use 1-2 hours before combination therapy of local correction with $0.01 \%$ solution of miramistin. In addition, a control group was formed, which included healthy women of reproductive age.

In order to study the pathogenesis of women of reproductive age in whom VVC is combined with BV, the concentration of cytokines and adhesion molecules in the blood was determined, namely the levels of IL-6 (test system BioSource Europe SA, Belgium), IL-8 (test systems BioSource Europe SA, Belgium), TNF- $\alpha$ (test systems BioSource Europe SA, Belgium), ICAM-1 (test systems Bender MedSystems GmbH, Austria) and VCAM-1 (test systems Bender MedSystems $\mathrm{GmbH}$, Austria), using the method of solid-phase enzyme-linked immunosorbent assay. To assess the effectiveness of treatment by different methods, such indicators were determined before and after treatment, and also compared with the corresponding indicators of the control group. In addition, we analyzed the results of studies of vaginal discharge for the presence of Candida albicans, non-albicans and «key» cells at 3, 7, 10, 14 days, and established the presence of recurrences 1, 3, 6 months after treatment. Such studies were performed by bacteriological method to determine the type of pathogen and its sensitivity to the drug used in the study. Statistical processing of the obtained data was performed using Student's $t$-test and $X^{2}[9,10]$.

\section{Results}

The study of the level of cytokines and adhesion molecules in women of reproductive age with VVC in combination with BV included in group I before treatment showed a statistically 
significant increase in such women ICAM-1 and VCAM-1, along with a significant increase in IL-6, IL-8 and TNF- $\alpha$ in comparison with the corresponding indicators of the control group, which indicates the presence of an inflammatory process due to a violation of the microbiocenosis of the vagina. After treatment with an antimicrobial combination drug (miconazole with topical metronidazole), the obtained values of these indicators differed statistically significantly in the direction of decrease from their values before treatment, which indicates a positive effect of treatment. However, in comparison with the control group, the values of almost all indicators after treatment still remained significantly elevated (Table 1).

Analysis of the results of evaluation of the obtained values of these indicators in group II before treatment also showed a significant increase in the levels of ICAM-1 and VCAM-1 in combination with a statistically significant increase in IL-6, IL-8 and TNF- $\alpha$, compared with the control group. After treatment with this drug in combination with a probiotic (lactobacilli) in candles, these indicators decreased significantly compared to the values before treatment, but some of them still remained significantly higher than in the control (Table 2).

Table 1

The content of cytokines and adhesion molecules in the serum of patients of group I $(\mathrm{M} \pm \mathrm{m})$

\begin{tabular}{|c|c|c|c|c|}
\hline \multirow{2}{*}{ Indicators } & \multicolumn{3}{|c|}{ Groups of examined patients } & \multirow{2}{*}{$\begin{array}{l}\text { Significance } \\
\text { level }(P)\end{array}$} \\
\hline & Control group $n=50$ & I group before treatment $n=50$ & I group after treatment $n=50$ & \\
\hline TNF- $\alpha(p g / m l)$ & $52.3 \pm 4.3$ & $79.9 \pm 1.4$ & $68.8 \pm 4.1$ & $\begin{array}{l}P_{(\mathrm{c}-\mathrm{Ib})}<0.001 \\
P_{(\mathrm{Ib}-\mathrm{Ia})}<0.01 \\
P_{(\mathrm{c}-\mathrm{Ia})}<0.01\end{array}$ \\
\hline IL-6 (pg/ml) & $107.3 \pm 8.2$ & $252.5 \pm 18.7$ & $188.5 \pm 7.9$ & $\begin{array}{l}P_{(\mathrm{c}-\mathrm{Ib})}<0.001 \\
P_{(\mathrm{Ib}-\mathrm{Ia})}<0.01 \\
P_{(\mathrm{c}-\mathrm{Ia})}<0.001\end{array}$ \\
\hline IL-8 (pg/ml) & $277.2 \pm 11.5$ & $337.5 \pm 9.7$ & $273.8 \pm 10.2$ & $\begin{array}{l}P_{(\mathrm{c}-\mathrm{Ib})}<0.001 ; \\
P_{(\mathrm{Ib}-\mathrm{Ia})}<0.001 \\
P_{(\mathrm{c}-\mathrm{Ia})}>0.05\end{array}$ \\
\hline ICAM-1 (ng/ml) & $5.3 \pm 0.4$ & $12.7 \pm 1.4$ & $7.4 \pm 0.5$ & $\begin{array}{l}P_{(\mathrm{c}-\mathrm{Ib})}<0.001 \\
P_{(\mathrm{Ib}-\mathrm{Ia})}<0.05 \\
P_{(\mathrm{c}-\mathrm{Ia})}<0.001\end{array}$ \\
\hline VCAM-1 (ng/ml) & $5.4 \pm 0.2$ & $10.8 \pm 0.3$ & $8.9 \pm 0.7$ & $\begin{array}{l}P_{(\mathrm{c}-\mathrm{Ib})}<0.001 ; \\
P_{(\mathrm{Ib}-\mathrm{Ia})}<0.001 \\
P_{(\mathrm{c}-\mathrm{Ia})}<0.001\end{array}$ \\
\hline
\end{tabular}

Table 2

The content of cytokines and adhesion molecules in the serum of patients of group II $(\mathrm{M} \pm \mathrm{m})$

\begin{tabular}{|c|c|c|c|c|}
\hline \multirow{2}{*}{ Indicators } & \multicolumn{3}{|c|}{ Groups of examined patients } & \multirow{2}{*}{$\begin{array}{l}\text { Significance } \\
\text { level }(P)\end{array}$} \\
\hline & Control group $n=50$ & II group before treatment $n=50$ & II group after treatment $n=\mathbf{5 0}$ & \\
\hline $\mathrm{TNF}-\alpha(\mathrm{pg} / \mathrm{ml})$ & $52.3 \pm 4.3$ & $78.9 \pm 2.1$ & $52.4 \pm 3.7$ & $\begin{array}{l}P_{\text {(c-IIb) }}<0.001 ; \\
P_{(\text {IIb-IIa) }}<0.001 ; \\
P_{\text {(c-IIa) }}>0.05\end{array}$ \\
\hline IL-6 (pg/ml) & $107.3 \pm 8.2$ & $240.3 \pm 16.9$ & $104.9 \pm 8.1$ & $\begin{array}{l}P_{(\mathrm{c}-\mathrm{IIb})}<0.001 ; \\
P_{(\mathrm{IIb}-\mathrm{II})}<0.001 ; \\
P_{(\mathrm{c}-\mathrm{IIa})}>0.05\end{array}$ \\
\hline IL-8 (pg/ml) & $277.2 \pm 11.5$ & $326.3 \pm 9.1$ & $269.3 \pm 10.2$ & $\begin{array}{l}P_{(\mathrm{c}-\mathrm{IIb})}<0.01 ; \\
P_{(\mathrm{IIb}-\mathrm{IIa})}<0.001 ; \\
P_{(\mathrm{c}-\mathrm{IIa})}>0.05\end{array}$ \\
\hline ICAM-1 (ng/ml) & $5.3 \pm 0.4$ & $13.3 \pm 1.4$ & $8.7 \pm 0.3$ & $\begin{array}{l}P_{(\mathrm{c}-\mathrm{IIb})}<0.001 ; \\
P_{(\mathrm{IIb}-\mathrm{IIa})}<0.01 \\
P_{(\mathrm{c}-\mathrm{IIa})}<0.001\end{array}$ \\
\hline VCAM-1 (ng/ml) & $5.4 \pm 0.2$ & $12.9 \pm 0.2$ & $6.9 \pm 0.2$ & $\begin{array}{l}P_{(\mathrm{c}-\mathrm{IIb})}<0.001 ; \\
P_{(\mathrm{IIb}-\mathrm{IIa})}<0.001 ; \\
P_{(\mathrm{c}-\mathrm{IIa})}<0.001\end{array}$ \\
\hline
\end{tabular}


In women of group III, as well as groups I and II, the values of the analyzed parameters before treatment were significantly higher than in healthy women, and after treatment according to the algorithm improved by the authors (additional use to combination therapy of local correction with $0.01 \%$ solution of the drug miramistin) they were statistically significantly reduced compared to pre-treatment values. At the same time, the indicators after treatment did not differ significantly from the values of the control group, which indicates the restoration of vaginal normocenosis and the effectiveness of the proposed algorithm for the treatment of women with VVC in combination with BV of reproductive age (Table 3 ).

Table 3

The content of cytokines and adhesion molecules in the serum of patients of group III $(\mathrm{M} \pm \mathrm{m})$

\begin{tabular}{|c|c|c|c|c|}
\hline \multirow{2}{*}{ Indicators } & \multicolumn{3}{|c|}{ Groups of examined patients } & \multirow{2}{*}{$\begin{array}{l}\text { Significance } \\
\text { level }(P)\end{array}$} \\
\hline & Control group $n=\mathbf{5 0}$ & III group before treatment $n=50$ & III group after treatment $n=50$ & \\
\hline $\mathrm{TNF}-\alpha(\mathrm{pg} / \mathrm{ml})$ & $52.3 \pm 4.3$ & $80.8 \pm 1.7$ & $51.7 \pm 2.1$ & $\begin{array}{l}P_{(\mathrm{c}-\mathrm{IIIb})}<0.001 ; \\
P_{(\mathrm{IIIb}-\mathrm{III})}<0.001 ; \\
P_{(\mathrm{c}-\mathrm{III})}>0.05\end{array}$ \\
\hline IL-6 (pg/ml) & $107.3 \pm 8.2$ & $244.7 \pm 17.2$ & $105.3 \pm 3.5$ & $\begin{array}{l}P_{(\mathrm{c}-\mathrm{IIIb})}<0.001 ; \\
P_{(\mathrm{IIIb}-\mathrm{III})}<0.001 ; \\
P_{(\mathrm{c}-\mathrm{III})}>0.05\end{array}$ \\
\hline IL-8 (pg/ml) & $277.2 \pm 11.5$ & $342.9 \pm 7.5$ & $269.9 \pm 10.3$ & $\begin{array}{l}P_{(\mathrm{c}-\mathrm{IIIb})}<0.001 ; \\
P_{(\text {IIIb-IIIa })}<0.001 ; \\
P_{(\mathrm{c}-\mathrm{III})}>0.05\end{array}$ \\
\hline ICAM-1 (ng/ml) & $5.3 \pm 0.4$ & $13.5 \pm 0.5$ & $4.4 \pm 0.4$ & $\begin{array}{l}P_{(\mathrm{c}-\mathrm{IIIb})}<0.001 ; \\
P_{\text {(IIIb-IIIa) }}<0.001 ; \\
P_{\text {(c-IIIa) }}>0.05\end{array}$ \\
\hline VCAM-1 (ng/ml) & $5.4 \pm 0.2$ & $12.9 \pm 0.4$ & $5.2 \pm 0.2$ & $\begin{array}{l}P_{(\mathrm{c}-\mathrm{IIIb})}<0.001 ; \\
P_{(\text {IIIb-IIIa })}<0.001 ; \\
P_{(\mathrm{c}-\mathrm{IIIa})}>0.05\end{array}$ \\
\hline
\end{tabular}

At the same time, the assessment of the clinical effect of treatment at different times showed no significant differences in treatment on day 3 (23 women with a positive effect in group I, 24 - in group II, 23 - in group III; $P>0.05$ ) and 7 day (40 women with a positive effect in group I, 41 - in group II, 43 - in group III; $P>0.05$ ). At the same time, on day 10 in group III the clinical effect was higher by $11.7 \%$ than in group I and by $6.7 \%$ than in group II (43 women with a positive effect in group I, 45 - in group II, 48 - in group III; $P>0.05$ ), and on day $14-$ by $8.9 \%$ compared with group I and $6.5 \%$ compared to group II (45 women with a positive effect in group I, 46 - in group II, 49 - in group III; $P>0.05$ ) [11].

When analyzing the frequency of relapses, it was found that in group I there were a total of 9 cases: after 1 month - in 3 women, after 3 months - in 2 women and after 6 months - in 4 women. As for group II, it recorded one case of recurrence after 1 month, after 3 and 6 months there were no such cases. In group III recurrences were not recorded at all $(P>0.05)$.

In combination, all the above indicates in favor of the highest effect from the application of the algorithm improved by the authors, especially in comparison with therapy with a combined drug.

\section{Discussion}

The microbiocenosis of the genital tract forms an endogenous ecosystem, and a woman's reproductive health depends on the balance of normal and opportunistic microflora. At the same time, this balance is very unstable and depends on both internal and external factors. Such factors include general infectious diseases, chronic stress, various extragenital diseases, nutritional factors, high sexual activity, etc. [12, 13].

Imbalance of the vaginal ecosystem leads to a variety of infectious and inflammatory processes, the most common of which are VVC and BV. They often bother pregnant women, because during pregnancy the immune system is reduced, resulting in violations of the microbiocenosis 
of the vagina become more pronounced. In turn, VVC and BV can cause a variety of complications during pregnancy, including threatened abortion and placental dysfunction [14, 15]. However, there is often a combination of them, which creates difficulties for both diagnosis and treatment. One of the reasons for this is the complex pathogenesis. In this regard, special attention was paid to the study of aspects of the pathogenesis of the combination of VVC and BV.

According to some researchers, vaginitis of bacterial and fungal etiology develops against the background of defects in the local immune system. Therefore, the study of the peculiarities of immune reactions in inflammatory diseases of the pelvic organs, especially of mixed etiology, remains relevant $[16,17]$.

To this end, the authors studied the serum concentration of cytokines and adhesion molecules, namely IL-6, IL-8, TNF- $\alpha$, ICAM-1 and VCAM-1. The expediency of their determination is explained by the fact that their level changes in response to the inflammatory process [18, 19], but, in contrast to the normocenosis, the combination of VVC and BV such a change in the elements of the immune system has not been fully studied. In this study, it was found that in women of reproductive age, in whom the pathology was detected, there was a significantly increased level of ICAM-1 and VCAM-1 with a simultaneous increase in the values of IL-6, IL-8, TNF- $\alpha$. After treatment, their values in all analyzed groups decreased significantly, but only in the group in which the authors improved the algorithm (additional use to the combination therapy of local correction with $0.01 \%$ solution of miramistin) the values of these indicators returned to healthy women, when significant differences between the values of the control group and group III after treatment was not observed.

The feasibility of additional use to the antimicrobial combination drug (miconazole with local metronidazole) is the drug miramistin due to its pronounced antimicrobial properties against gram-positive and gram-negative bacteria, pathogenic fungi, some viruses and protozoa, as well as its ability to increase bacterial and bacterial therapy, etc. [20, 21]. This was confirmed by the obtained clinical results, when in group III on day 10 the clinical effect was $11.7 \%$ higher than in group I and $6.7 \%$ than in group II, and on day 14 - by $8.9 \%$ compared to group I and $6.5 \%$ compared to group II.

One of the problems in the treatment of disorders of the microbiocenosis of the vagina is often the occurrence of recurrences. The need to reduce them was one of the factors in improving this algorithm. As a result of the obtained data, its use made it possible to avoid cases of recurrence of VVC in combination with BV, which indicates, together with the above results, the effectiveness of such an algorithm.

Study limitations. The study did not include women with acute diseases of the pelvic organs (upper parts), with specific sexually transmitted infections (gonorrhea, trichomoniasis, etc.), TORCH-infections, with prior therapy with antimicrobial and antifungal drugs for 1 month before the visit, and also pregnant women, nursing mothers.

Prospects for further research. Study of the pathogenesis and possibilities of reducing the recurrence rate of VVC in combination with $\mathrm{BV}$ in pre- and postmenopausal women.

\section{Conclusions}

As a result of the study, the possibility of using the authors' improved treatment algorithm for VVC in combination with BV in women of reproductive age was substantiated in order to reduce the frequency of their recurrence. In addition, it was found that in the case of this pathology there is an increase in the level of pro-inflammatory cytokines (IL-6, IL-8), TNF- $\alpha$ and ICAM-1 and VCAM-1. The use of such an algorithm makes it possible to increase the clinical efficacy of VVC treatment in combination with BV in women of reproductive age (by $11.7 \%$ compared with group I and $6.7 \%$ with group II on day 10; by $8.9 \%$ compared with group I and $6.5 \%$ with group II on day 14), to avoid their recurrence to $100 \%$ of those treated, as well as to restore the values of these indicators to normal.

\section{Conflict of interest}

The authors declare that they have no conflicts of interest. 


\section{References}

[1] Van de Wijgert, J. H. H. M., Jespers, V. (2017). The global health impact of vaginal dysbiosis. Research in Microbiology, 168 (9-10), 859-864. doi: http://doi.org/10.1016/j.resmic.2017.02.003

[2] Brown, R. G., Marchesi, J. R., Lee, Y. S., Smith, A., Lehne, B., Kindinger, L. M. et. al. (2018). Vaginal dysbiosis increases risk of preterm fetal membrane rupture, neonatal sepsis and is exacerbated by erythromycin. BMC Medicine, 16 (1). doi: http:// doi.org/10.1186/s12916-017-0999-x

[3] Schlabritz-Loutsevitch, N., Gygax, S. E., Dick, E., Smith, W. L., Snider, C., Hubbard, G., Ventolini, G. (2016). Vaginal Dysbiosis from an Evolutionary Perspective. Scientific Reports, 6 (1). doi: http://doi.org/10.1038/srep26817

[4] Nelson, T. M., Borgogna, J.-L. C., Brotman, R. M., Ravel, J., Walk, S. T., Yeoman, C. J. (2015). Vaginal biogenic amines: biomarkers of bacterial vaginosis or precursors to vaginal dysbiosis? Frontiers in Physiology, 6. doi: http://doi.org/10.3389/ fphys.2015.00253

[5] Amabebe, E., Anumba, D. O. C. (2018). The Vaginal Microenvironment: The Physiologic Role of Lactobacilli. Frontiers in Medicine, 5. doi: http://doi.org/10.3389/fmed.2018.00181

[6] Ceccarani, C., Foschi, C., Parolin, C., D’Antuono, A., Gaspari, V., Consolandi, C. et. al. (2019). Diversity of vaginal microbiome and metabolome during genital infections. Scientific Reports, 9 (1). doi: http://doi.org/10.1038/s41598-019-50410-x

[7] Lohse, M. B., Gulati, M., Johnson, A. D., Nobile, C. J. (2017). Development and regulation of single- and multi-species Candida albicans biofilms. Nature Reviews Microbiology, 16 (1), 19-31. doi: http://doi.org/10.1038/nrmicro.2017.107

[8] Dadar, M., Tiwari, R., Karthik, K., Chakraborty, S., Shahali, Y., Dhama, K. (2018). Candida albicans - Biology, molecular characterization, pathogenicity, and advances in diagnosis and control - An update. Microbial Pathogenesis, 117, $128-138$. doi: http://doi.org/10.1016/j.micpath.2018.02.028

[9] Polidanov, M. A., Blokhin, I. S., Skorokhod, A. A., Alieva, S. G., Scherbakova, I. V. (2020). Poniatie i znachenie kriteriia stiudenta v klinicheskoi meditsine. Modern Science, 2-1, 227-230.

[10] Mintser O. P. (2017). Statystychni metody doslidzhen pry vykonanni naukovykh doslidzhen. Praktychna medytsyna, 7, 43-50.

[11] Pandey, S. A. (2020). Combination of candida vulvovaginitis and bacterial vaginosis: optimization of diagnostics and treatment for the women of genesial age. Reproductive health of woman, 3, 32-35. doi: http://doi.org/10.30841/2708-8731.3.2020.215012

[12] M.M., R. (2020). Clinical And Epidemiological Features Of Bacterial Vaginosis. The American Journal of Medical Sciences and Pharmaceutical Research, 2 (8), 140-145. doi: http://doi.org/10.37547/tajmspr/volume02issue08-21

[13] Li, J., McCormick, J., Bocking, A., Reid, G. (2012). Importance of Vaginal Microbes in Reproductive Health. Reproductive Sciences, 19 (3), 235-242. doi: http://doi.org/10.1177/1933719111418379

[14] Lubkovska, O. (2020). Comparative aspects of placental dysfunction in women using different methods of contraception in anamnesis. EUREKA: Health Sciences, 5, 34-40. doi: http://doi.org/10.21303/2504-5679.2020.001416

[15] Zheng, N., Guo, R., Yao, Y., Jin, M., Cheng, Y., Ling, Z. (2019). Lactobacillus iners Is Associated with Vaginal Dysbiosis in Healthy Pregnant Women: A Preliminary Study. BioMed Research International, 2019, 1-9. doi: http://doi.org/10.1155/2019/6079734

[16] De Seta, F., Campisciano, G., Zanotta, N., Ricci, G., Comar, M. (2019). The Vaginal Community State Types MicrobiomeImmune Network as Key Factor for Bacterial Vaginosis and Aerobic Vaginitis. Frontiers in Microbiology, 10. doi: http:// doi.org/10.3389/fmicb.2019.02451

[17] Hruzevskyi, O. (2020). The cytokine system's status in bacterial dysbiosis and bacterial vaginosis. ScienceRise: Medical Science, 3 (36), 50-56. doi: http://doi.org/10.15587/2519-4798.2020.204094

[18] Masson, L., Barnabas, S., Deese, J., Lennard, K., Dabee, S., Gamieldien, H. et. al. (2018). Inflammatory cytokine biomarkers of asymptomatic sexually transmitted infections and vaginal dysbiosis: a multicentre validation study. Sexually Transmitted Infections, 95 (1), 5-12. doi: http://doi.org/10.1136/sextrans-2017-053506

[19] Campisciano, G., Zanotta, N., Licastro, D., De Seta, F., Comar, M. (2018). In vivo microbiome and associated immune markers: New insights into the pathogenesis of vaginal dysbiosis. Scientific Reports, 8 (1). doi: http://doi.org/10.1038/ s41598-018-20649-x

[20] Kirichenko, I. M. (2013). Ispolzovanie preparata Miramistin ${ }^{\circledR}$ pri infektsionnoi patologii v ginekologii. Poliklinika, 6, 98-100.

[21] Mironova, A. V. (2016). Vozmozhnosti primeneniia preparata Miramistin ${ }^{\circledR}$ v praktike detskogo ginekologa (obzor literatury). Effektivnaia farmakoterapiia, 14, 42-46.

Received date

Accepted date

Published date 29.01.2021
(C) The Author(s) 2021

This is an open access article under the CC BY license (http://creativecommons.org/licenses/by/4.0). 